\title{
Social Character of Science and Its Connection to Epistemic Reliability
}

\author{
Natalia Fernández ${ }^{1}$ (D) Federico Benitez ${ }^{2}$ (D) Diego Romero-Maltrana ${ }^{3}$ D
}

Accepted: 29 September 2021 /Published online: 22 October 2021

(c) The Author(s), under exclusive licence to Springer Nature B.V. 2021

\begin{abstract}
Scientific research is a human endeavour, performed by communities of people. Disproportionate focus on only some of the features related to this obvious fact has been used to discredit the reliability of scientific knowledge and to relativize its value when compared with knowledge stemming from other sources. This epistemic relativism is widespread nowadays and is arguably dangerous for our collective future, as the threat of climate change and its denialism clearly shows. In this work, we argue that even though the social character of science is indeed real, it does not entail epistemic relativism with respect to scientific knowledge, but quite the opposite, as there are several characteristic behaviours of this specific human community that were built to increase the reliability of scientific outputs. Crucially, we believe that present-day scientific education is lacking in the description and analysis of these particularities of the scientific community as a social group and that further investing in this area could greatly improve the possibilities of critical analysis of the often very technical issues that the citizens and future citizens of our modern societies have to confront.
\end{abstract}

\section{Introduction}

As every human activity, science is in part socially constructed: scientists are culturally embedded and have interests driving their efforts other than the pure love for truth and knowledge. We do not attempt here to argue against these issues as it would be pointless. However, in this work, we argue that disproportionate attention to a restricted set

Natalia Fernández

natalia.fdez.f@gmail.com

Federico Benitez

federico.benitez.conte@gmail.com

Diego Romero-Maltrana

diego.romero@pucv.cl

1 Facultad de Ciencias, Pontificia Universidad Católica de Valparaíso, Avda. Universidad 330,

Curauma, Valparaíso, Chile

2 Université de Lausanne, 1015 Lausanne, Switzerland

3 Instituto de Física, Pontificia Universidad Católica de Valparaíso, Avda. Universidad 330, Curauma, Valparaíso, Chile 
of features that stem from science's social character and its cultural embeddedness have promoted the erroneous belief that scientific knowledge is not trustworthy and have raised questions concerning the suitability of science education, up to the point that a renowned science education journal decided to devote a whole number to the problem. We will call these erroneous beliefs the problem of 'epistemic relativism.'

Epistemic relativism has been diversely defined (Luper, 2004; Sankey, 2011) but here, we mention only two main forms: subjective relativism and pluralistic relativism. The subjectivist view denies that there exists any correct account of reality because there is no epistemic standard that can provide it, while the pluralist defends the existence of many such standards - and eventually many correct views of reality. For the purposes of this discussion, the social character of science has been used on several occasions as a justification for both these epistemic relativist positions, while at the same time both these positions have shown to be dangerous for our societies, so we do not make a strong distinction between them in what follows.

Epistemic relativism is not just a feature of personal beliefs with no important consequences outside of a subject's internal worldview. It is a deep social issue affecting the life of millions and even the equilibrium of our ecosystems. For example, it is increasingly patent that human actions are not innocuous for the environment, and it is beyond hopeless to tackle these challenges without the aid of our best science and a consensus on the implications of this science. Therefore, it is of the highest importance to strengthen the trust that people have in science, which we argue to be the most reliable source of knowledge available. In this work, we identify how the epistemic relativist views emerge and why they are greatly exaggerated, and we highlight how they underestimate the features of science that are built to protect its products from bad practices.

There are several of such features, such as the methodological pursue of independence from values, of objectivity, and about the reliability of evidence. Many of these have been already studied in the relevant literature (Guyatt et al., 1992; Franklin, 1994; Douglas, 2004; Betz, 2013; Koskinen, 2020), and some of which have a long, if sometimes forgotten history within philosophy of science, such as the epistemological views of Bachelard (1984). In particular, there is one characteristic of science useful to shield it from epistemic relativism that, to the best of our knowledge, has been absent from the general discussion: namely, the very social character of science. Here, we argue that although some of science's social characteristics, shared also by other human activities, might promote the idea that science is as reliable as any other epistemic source, there are some peculiar characteristics of science as a social endeavour that are perhaps unique to the activity, which promote it to be the most reliable source of knowledge available and protect science from being overrun by epistemic relativism.

Having argued for this, our work stresses the importance of including these central features of the scientific endeavour within science education considered in its most general sense; that is, not only within the context of formal schooling, but also for preservice teachers and outside academia for the broad society, as the timescale of changes in the modern world is not compatible with the time requirements of formal education.

The structure of this article is as follows: in Section 2, we show those facts, which we are not debating, that are connected to relativistic positions; in Section 3, we show how these relativistic positions have been articulated; in Section 4, we show how this relativism has had practical consequences at a global level, in other words, we show why it is problematic. In Section 5, we focus on arguing that despite that the facts stated in Section 2 are undeniable, science has self-correction tools that allow us to avoid falling into 
epistemic relativism; in Section 6, we highlight the urgency of taking these elements of self-correction to different educational levels, to finally conclude in Section 7.

\section{Science and Postmodern Disillusionment}

Science, like every human activity, is not exempt from the influence of the culture surrounding the scientists that make it. It is prone both to noble endeavours-finding cures for diseases, radically diminishing child mortality, technologically improving human quality of life, and so on - and to less altruistic tendencies, usually aligned with the interests of the powerful and the rich. Along its history, it is undeniable that science has been influenced by politics, economics, and the ambitions of several interest groups. Not only that, but the dynamics of the scientific community bring with it a host of competing priorities, which sometimes might trump over the declared values of science. Examples of this include the structure of academic incentives that exists around the writing of scientific publications. Academic job precariousness, stringent funding mechanisms, and other economic pressures strongly promote the publication of as many academic articles as possible. This can go against the overall quality of research and in extreme cases can even lead to rushed consensus within the academic community.

On top of this, the very notion that scientific knowledge is empirical has been put into question, on several fronts. For example, there is the fact that an increasing portion of scientific research is based on computer simulations and not on direct observations of natural phenomena. This not only takes place in extremely complex systems such as climate (Flato et al., 2014) or biochemistry (Bonate, 2011; Van Gunsteren \& Berendsen, 1990), but also at the most fundamental level of the physics of particle accelerators (ATLAS, C 2010; Lukas, 2012).

We believe that these kinds of facts have promoted extreme visions. The idea about simulations becoming so dominant has led some scientific educators to claim that science is not always empirically based (McComas et al., 1998; Pozo, 1997). We believe that such claims underestimate the role played by empirical data in the construction of simulations, as the trust and the extended use of simulations is justified mostly by how they are empirically validated. However, in this work, we do not focus on these sources of concerns about scientific knowledge, but only around three specific issues: the relation between power and science which led to certain postmodern views, the social character of science and its role in science development leading to extremes readings of Kuhn and social constructivism, and extreme readings of Popper falsifiability criterion leading to relativist takes on science.

It is easy to find examples of science being directed by external social factors. There is the well-documented example of huge investments in fundamental physics generated by war, a particularly clear example of which are the world wars - the Manhattan project being a famous case of this - and the cold war afterwards (Rhodes, 2012). It is also clear in the case of the denial, by certain groups of well-financed scientists, of the growing consensus about health problems created by tobacco, and of anthropogenic climate change (Oreskes \& Conway, 2011).

It is also patent that science is not completely neutral when it comes to the search of solutions to issues that affect humankind, but that research funding tends to be concentrated on topics that are important for the rich or powerful. An example of this is the uneven distribution of research on illnesses or diseases affecting developed countries compared to those affecting the more populated underdeveloped ones (Kremer, 2002). 
This is arguably a simplistic view of a complex issue that should and has been covered with greater detail (see for example, Resnik, 2007) for our purposes this partial sketch is enough to claim that relationships such as these between scientific programmes and products, and motivations other than a pure search for truth, are partially responsible for an increasing scepticism about science, and have done a lot of harm to the image of the scientific enterprise.

All this is embedded within a generalized disillusionment with the promise of sciencebased progress. Indeed, many modernist visions of the future of humanity have not come to pass, with examples ranging from big promises such as a world-ranging democracy or infinite clean energy from nuclear fusion to more trivial ones such as flying cars or hotels on the moon. One of the most recent such disillusionments is related to the exponential growth of communication technologies, in particular the internet and the appearance of social media. These developments brought with it the promise of a form of illustration for humankind, and of new ways of exerting and increasing democracy worldwide. As it turned out, there is a broad view that social media and the internet has mostly amplified polarization, and its effect on democracy is at best ambiguous, with the internet being used in some regions of the world for the benefit of authoritarianism (Best \& Wade, 2009; Rocca, 2011).

It is not surprising then that people would abandon their faith in the big narratives of modernism. The speed with which technology changes our lives, and with which the sheer amount of information humanity acquires increases makes it almost impossible to predict the problems and social demands that will confront people in twenty or fifty years-much less allow for a narrative of linear progress. The world science has brought to us seems to be much more unstable than the one it promised.

Another source of concern comes from (radical) theory change in science. It seems to be a pointless effort to demonstrate the astonishing and sustained progress of science since Galileo's times to date. Nowadays, our world view is much richer and complex compared with the one we hold just a few decades ago. This is not just some quantitative change, that is, it is not just that we know an increasing amount of data concerning the same things, but it constitutes qualitative change, as contemporary theories tell a different (often less intuitive but increasingly self-consistent) story about how the material world behaves. Such a sharp change can be recognized in the passage from a geocentric model to a heliocentric conception of the universe, in the passage from Newtonian mechanics to special relativity, in the passage from phlogiston theory to oxidation, or from creationist ideas to evolution theory, among many others.

The obvious fact of the qualitative change of scientific knowledge hides a less obvious premise: these changes would not be possible if all our theories about the world would retain their alleged truth value. What was once believed to be truth cannot be valid any longer if our current state of knowledge is assumed to be better than the one that was held before. This severely undermines the alleged truth of our current scientific description of the world.

All of this is compounded by the famous problem of the demarcation of science; that is, the problem of finding a set of criteria to separate scientific from non-scientific knowledge. This problem has a long history, and a consensus has formed around the fact that it has no solution. As Laudan (1983) convincingly argues, none of the past attempts would be accepted by most philosophers, and for good reasons. Finding criteria that puts together 
astronomy, palaeontology, particle physics, and ecology is hard enough, even before having to exclude astrology, creationism, homeopathy, and other pseudo-sciences. ${ }^{1}$

All these facts have been used to justify what we would describe as an exaggerated counter-reaction to the positivist view of science, a reaction that ends promoting what amounts to epistemic relativism. At the end of the day, it is hardly surprising that many of these issues, most of which are common to every human activity, are also part of the scientific endeavour. We acknowledge the influence that these factors can have in the day to day functioning of science, but also do many scientists themselves. Among these reactions to these real, well-documented issues, some of them are pushed to extremes where the objective, epistemically privileged character of scientific knowledge is put into question, whereas others put into question its very pertinence for our society.

\section{From Disillusionment to Epistemic Relativism}

The previous section highlights some characteristics of the scientific endeavour that, we claim, are undeniable facts. These facts arguably played a role in the development of some relativist views that are disproportionate and ill-founded.

The first group of facts mentioned in the previous section are examples of the relationship between scientific efforts and motivations other than the pursuit of pure knowledge, be it war or political influence, economic interests, and so on. These are part of the reasons that promoted the cultural pass from modern to postmodern views. Modernism is characterized by the utopian promise of a unified political, ethical, and economical progress for all humanity, based on reason and on science as a paradigmatic example of reason. Postmodernism is characterized by the negation of such monolithic views.

Postmodernist thinkers highlight the existence of many views in every topic, be it politics, economics, moral views, culture in general, even science, stressing the equal value of them all, or perhaps more accurately, stressing that no particular view holds a privileged position, not even science (Lyotard, 1979; Peters, 1995). Prominent figures such as Lyotard (1979) extended the unfortunate cases of political or economic power influence over science to a norm of the whole scientific enterprise, and Gianni Vattimo, in an analogy to the theory of relativity in physics, declared that as time depends on the relative position of the observer, the truth about facts is relative to who interprets those facts (Vattimo \& Webb, 1992), embracing in this way a full blown epistemic relativism which assigns to science and scientific theories the same epistemic value as any other belief, independently of how such belief is founded.

Another source of concern mentioned in the previous section is the constatation of theory change in science. The fact that our understanding of the world has changed so dramatically famously led Kuhn to recognize 'temporal blocks' of unified theoretical thinking, where a community of experts share theoretical and experimental technologies and share the kind of problems that occupy them and the way of solving such problems. Kuhn called those temporal blocks 'paradigms' and 'paradigm change' to the replacement of one block for another (Kuhn, 1962).

\footnotetext{
${ }^{1}$ There have been recent attempts within science education (Irzik \& Nola, 2011; Irzik \& Nola, 2014) to use the notion of family resemblance between the sciences for achieving certain characterization of scientific knowledge, although still short of a total demarcation.
} 
A key point for our purposes is that Kuhn postulated the incommensurability of competing paradigms, that is, he claimed that two different blocks are so radically different that although both paradigms might use what seems a priori the same concepts, the meaning of those concepts in each paradigm is different, and therefore, the people formed under a paradigm cannot really communicate with people formed under the other. The passage from one paradigm to the next would therefore constitute a radical change with no elements in common, which would imply that there is no progress in science, nor truth in its products, nor rationality in the dynamics that make scientific ideas evolve. This is a sketch of the most radical interpretation of Kuhn's work, an interpretation that the late Kuhn himself would not adhere to. However, these philosophical ideas in its radical form present science as an irrational enterprise, and they have been tremendously influential within the context of science education (Matthews, 2002).

Mathews analyses Kuhn's ideas and how their acceptance evolved inside the educational community, to conclude that.

...The science education community is as guilty as any other of the charge of misunderstanding Kuhn, and drawing relativist and subjectivist epistemological conclusions. There has been very little prolonged engagement with his writings, and even less prolonged critical engagement. As Loving and Cobern stated in their review 'None of the articles examined (...) offered any real critique of Kuhn's positions,' and the science education community has become a 'admiration society for Thomas Kuhn' (Loving \& Cobern, 2000). (Cited in Matthews, 2002, p. 112)

The relation between Kuhn's ideas and what came to be known as constructivist epistemologies is clear from the citation analysis performed by Loving and Cobern (2000). Both approaches (an extreme and literal interpretation of the early Kuhn and constructive epistemology) support the unfortunately extended claim that some natural objects are 'just' man-made concepts.

There are two different traditions with regard to constructivism in education. On the one hand, there is what is known as psychological constructivism, with examples such as Piaget's insistence on the centrality of the learning individual within the construction of knowledge and Vygotsky's proposal of learning as a language-mediated social interaction. On the other hand, there is what is known as sociological constructivism (Durkheim), by which scientific knowledge is generated and justified socially, within social circumstances that shape the beliefs of individuals (Matthews, 2014). This second version makes a direct appeal to the nature of scientific knowledge and, in particular, enlarges the social character of sciences to the point of proposing that all scientific knowledge is created instead of discovered.

These perspectives of constructivism in science education put into question the separation between the observer and the world, making the former part of scientific explanations, and understanding knowledge as a systematic cognitive process in which the subject creates reality, as opposed to perceiving it in a passive way. These ideas have influenced the creation of study plans and didactic practices (Matthews, 2014). The notion that there are atoms, cells, or energy somewhere outside of us, really existing, and waiting to be discovered, is directly opposed to the epistemic assumptions of constructivism, while at the same time, the latter is explicitly or implicitly adopted by most teachers (Lederman et al., 2002) and naturally by most students. "Once the "positivist glaciation" was overcome, today the assumption seems to be that science is not a discourse about "the real" but instead a socially defined process consisting in the elaboration of models to interpret reality' (Pozo, 1997, p. 93, our translation). 
The tentative character of scientific knowledge also gives rise to a certain kind of relativism, by which different interpretations of the information provided by science are considered equally valid for building a personal opinion. Science educators, for the most part, have not tried to give a realist, fallibilist interpretation to scientific terms, following instead the line of constructivism in education (Tobin, 1999).

Finally, the last position that we identified as an unhealthy extreme is the literal take on falsifiability related to the problem of the demarcation of science. Popper's falsifiability is a very influential post-positivist criterion of demarcation that ultimately fails. For Popper, science distinguishes itself by continually generating predictions that can falsify it: if a scientific hypothesis predicts a certain experimental outcome, and this does not come to pass, then the hypothesis should be discarded. This would be different to how other types of knowledge - such as psychoanalysis or religion-work: in these cases, if a given fact goes against a certain belief or idea, then a way to explain this fact away is found, in order not to challenge the belief. Notice the normative dimension of this proposal, which many scientists since have taken to heart, even though, as was quickly pointed out by Quine, science does not really work this way, as it is impossible to separate any individual hypothesis from a whole corpus of theory and experimental procedures. An extreme take on falsifiability imposes extremely lofty standards on several scientific branches (in particular, those based on statistical analysis), standards which are technically impossible to achieve: thus, a blind adherence to falsifiability promotes mistrust on sound scientific results, leading to forms of epistemic relativism.

Most of these visions on the nature of science are reasonable up to a point but have given way to exaggerated takes that seem to impose absolute views on the nature of knowledge-the very issue that they attempted to solve in the first place. In other words, they demand from scientific knowledge a level of reliability that it is impossible to attain, they show that no human knowledge can ever attain this level of reliability, and they use this as an argument against scientific knowledge-but it is not real-world science they are attacking, but their own idealized views.

This seems to be quite abstract, but extreme relativistic takes on the nature of scientific knowledge have important consequences that affect the relationship between humans and their environment, as exemplified by the anti-vaxxer movement and the environmental impacts of human industry, among other issues that we discuss below.

\section{Relativism About Science and Global Issues}

The relationship between humans and their environment is increasingly harmful for the latter. It is impossible to ignore the negative impact that we as a species have on our planet, exploiting resources beyond what is sustainable, generating and accelerating changes at the level of the biosphere and the climate, and in general altering the diverse equilibria at work around us. These facts are extremely relevant also when considering science and science education, as an adequate understanding of science provides a clear path to grasping the interrelationship between man and nature. The aim of this section is to show how ignoring the input of science at the time of taking social and environmental decisions leads us to dangerous scenarios, where the power of the few stomps over the common good and where 'alternative' facts are thrown around as equally valid than those coming from experts. We proceed by mentioning some well-documented events that are useful as examples of these issues. 
In 2017, then US president Donald Trump announced that the USA would withdraw from the Paris Climate Agreement, a global, legally binding international pact that commits countries to take actions against human-induced climate change. By reducing emissions, the objective is that the average global temperature rise stays below $2{ }^{\circ} \mathrm{C}$. The USA represents around $15 \%$ of the global emissions of greenhouse gases, a contribution which, needless to say, is relevant to the goal of the agreement. On top of that, the US retirement from the agreement generates a confidence problem, being as they are the strongest and biggest world economy (Tollefson, 2017).

The goal of $2{ }^{\circ} \mathrm{C}$ is extremely ambitious, as e.g., just the emissions related to activities necessary for the global food system threaten its achievement (Clark et al., 2020) which makes even more pressing the political agreement and combined effort of all relevant actors. Unfortunately, not only prominent figures have set this goal in danger by omission (as the US withdrawal of the Paris Climate Agreement just mentioned) but also have actively promoted activities that directly threaten the environment, such as the financialization of fossil fuels to the detriment of cleaner forms of energy (Jerneck, 2017), or the promotion of deforestation of large areas to boost local economy, among them the Amazonas, the so-called world's green lungs (Malhi et al., 2008; Phillips, 2019; Symonds, 2019).

Industries with high environmental impacts do not only use their influence over politicians in power to boost their businesses, but they also use powerful ideas to justify their lobbying. Popper's ideas specifically have been used to rise impossibly ambitious standards of proof, in order to deny statistical evidence in favour of the anthropogenic origin of the present rise in average global temperature. Berry et al. claim:

Using a Popperian approach, Michaels (2015) and Michaels and Knappenberger (2015) provide a test of whether climate models are actually simulating reality. They conclude that the models suggest a degree of sensitivity of temperature changes to $\mathrm{CO}_{2}$ that does not exist. As a result, the models overpredict temperature increases. (Berry et al., 2016, p. 597)

These claims appear in the Cato journal, depending on the Cato institute, which is a libertarian leaning think tank with known links to big oil. As also happened with the aforementioned case of extreme interpretations of Kuhn's ideas, Popper's philosophical proposals about the nature of science have sometimes been accepted as dogmas, in an uncritical way.

The impact of climate change threatens the sustainability of valuable and needed natural resources (Barange et al., 2010). A change in our way of life and of production is urgent, and such changes are predominantly political in nature. If such decisions are not informed and consistent with our best scientific knowledge, our future may be harder, with more misery and suffering than in any previous time in history. A political future in a world (hopefully) governed by democracies can only align to scientific evidence if the global population understands and trusts science and the knowledge it produces. Science education has a significant role to play in this.

Another example of the importance of trusting science and the pressing need of avoiding views that lead to epistemic relativism is connected to the difficult situation most of us have been going through during the pandemic caused by the COVID-19 disease. There is not only a major sanitary crisis with over 2.79 million people dead to date, the drama is not just related to the families, friends, and colleges of each of the 2.79 million, but to virtually everyone, as this new scenario has changed the way we interact with each other, the way most of us work, and because millions have lost their jobs due to the enormous impact that the pandemic had on economy (Fernandes, 2020). 
In such a complex scenario there has been a proliferation of false information and conspiracy theories (Ball \& Maxmen, 2020; Bastani \& Bahrami, 2020), with people believing that the virus was created in a laboratory with evil purposes, some people believing that the vaccine is Bill Gates' plot to insert a chip on us and to spy or control us; creating and scenario in which for these and other equally unfounded reasons, there are groups of people that try to convince everyone they can that vaccines are dangerous in one way or another. Recent studies show that there are still more people pro than anti-vaccination; however, theoretical models predict that such tendency might revert in 10 years from now under the present conditions (Johnson et al., 2020). Unvaccinated groups of people are not just being irresponsible with themselves, but they are also a threat to the community they are inserted into. Measles outbreaks in the USA years after the disease was eradicated is a sad example of this (Chen et al., 2011; Sugerman et al., 2010). The testimony of an experienced paediatrician (see Tayloe, 2021) is far more eloquent than what we could attempt in a few lines. It is increasingly important to restore people's trust in science and, once more, science education has a leading role to play in this important task.

\section{Self-correcting Features of Science}

Up to this point two things should be clear from our discussion: first and foremost, it is of the highest importance that science practice in general (i.e. how scientific knowledge is developed) and scientific claims (i.e. scientific knowledge itself) start to be taken seriously by everyone, as it seems to be the only way for those making decisions with global impacts - in a world in which these decisions will ideally be taken in a democratic way-to make choices with the fate of our planet and the whole human race in sight, and not only their own personal agendas, and second, that science in general and scientific claims in particular are not free of issues, and not everything that is associated with science has to be adopted and followed blindly.

These two preliminary conclusions seem to be at odds with each other, but in fact they are not. To adopt well-established scientific claims as true or approximately true, it is the most rational position, ${ }^{2}$ because although science has flaws (as shown is Section 2), it also has unique self-correcting mechanisms. It is not by blindly following science that we can make better informed decisions, but by learning what are the mechanisms the scientific community must deal with its issues, that we can achieve a state of informed trust in what is in fact mankind's most reliable epistemic endeavour.

Regarding the relationship between money/power and science, although sadly undeniable, most of the time, this relation is responsible for manipulating the direction of research, but not the results. For example, many scientists are currently directing their efforts to studying whatever is related to the coronavirus strain that is affecting the globe, and a larger investment than usual is destined to infectiology, but this fact does not make the scientific results any less (nor any more) closer to the truth than they would be otherwise, for as long as the research is conducted rigorously, following strict standards, and overcoming the

\footnotetext{
2 The philosophical stance that roughly claims that science delivers truth or approximate truths is called 'scientific realism' (see Psillos, 1999). It is fair to say that the contemporary discussion in general philosophy of science is dominated by 'scientific realism' and the ways it defends from Laudan's 'pessimistic meta-inductive argument' (see Laudan, 1981), particularly the different forms of what has been called 'selective realism' (Chakravartty, 2007; Ladyman et al., 2007; Worrall, 1989).
} 
barriers of scientific publications. In a world where resources are scarce, both economical and human, it is normal that some areas will be prioritized over others and recognizing this fact can open the door to more democratically chosen priorities (at least when speaking of public sector research). But a larger investment in specific areas does not logically imply that the products of scientific research are any less reliable or trustworthy, and the expression "socially constructed" takes in this context a vastly different meaning than the one implied by constructivism. In other words, if the social construction of scientific knowledge stands for the fact that there are social forces partially steering research topics, no epistemic relativism about this knowledge is warranted.

But of course, this is not the only sense in which scientific knowledge has been classified as socially constructed, and other senses have more profound impacts on our perception and trust of scientific knowledge. We described in Section 2 some insights from the philosophy of science that also show the social character of scientific knowledge. The fact that accepted scientific knowledge changes in time led Kuhn and his followers to social constructivist visions. But there is more nuance here than what some authors have taken out of Kuhn's ideas. The fact that scientists play a social game of giving and asking for justifications of their findings in no way takes value from scientific knowledge but is instead one of the mechanisms to test the validity of scientific knowledge, one that it has not been discussed in the related literature to the extent that it deserves. 'Socially constructed' does not mean the same in science as in football, as the rules of the game of doing science are adapted to the task of searching for a reliable knowledge of nature, a fact which has epistemic significance.

Science as a discourse is heavily constrained; in fact, it is the most constrained of all human discourses. Even if it is true that changes in scientific knowledge are validated and negotiated among scientists, the means by which these validations work go beyond mere social dynamics. The object of scientific research is the natural world, and at the end of the day, the scientific discourse must correspond to the functioning of the natural world that it describes, in terms of experimental results, observational predictions, consistency with previous observations, etc. Scientific knowledge is not only about agreements among scientists. Interestingly, in the first half of the XX century, Bachelard already proposed to view the scientific discourse within the community of scientists as a specific rational discourse which embeds the epistemic rules for attaining dependable knowledge about nature (Bachelard, 1984 for the English translation). The language of science is that of rationality, in the sense that scientific knowledge must be logically self-consistent, and any newly proposed finding must be logically consistent with previous knowledge — or provide good reasons to think that this previous knowledge is wrong. This puts a further constraint on what kind of discourse science can provide, although admittedly this particular constraint is shared with other types of knowledge (including philosophy or the humanities in general).

So far, we have been using "scientific knowledge" in a very general way, but philosophers of science (Hoyningen-Huene, 1987) make the distinction, truly relevant for this work, between the context of discovery and the context of justification when considering scientific knowledge. The mechanisms that the scientific community uses to accept a piece of knowledge differ in these two instances. When a scientific group is searching for new knowledge, there is space for non-rational choices, and for intuition to play a role. In the discovery phase, the scientific community plays a guidance role, marking some subjects or phenomena as promising or important for new ideas and research. Some of these decisions do involve extra-scientific information: aspects of ethics, aesthetics, economics, politics, and many others can play a role in deciding what are the possible ideas to be tested, phenomena to be explored, etc. 
But for a certain piece of knowledge to be accepted as scientific, it has to be evaluated in stricter terms, using formal mechanisms such as peer review. It is then that science has procedures to deal with subjectivity, human error, and human malice. In this context of justification, the role of the scientific community is completely different, and much more constrained - and constraining. Scientists are expected to attack any new proposal (and usually do in scientific conferences, where very heated exchanges over arcane topics regularly happen), and the proponents of a new piece of scientific knowledge are expected to defend their ideas by means of rationality, consistency with existing knowledge, replicability, and so on.

In a twist of the constructivist critiques of science, it is precisely its social character that makes scientific knowledge more reliable. The logical positivists were wrong in that knowledge does not stem directly from any source - it is always holistic, so that there is no clear distinction between theory and experimental observations, for example. But this is not only valid for scientific knowledge. As postmodernists argue well, all propositional knowledge is discourse, all discourse is language, and all language is holistic-meaning always depends on a network of interrelated meanings. There is no unshakeable basis upon which knowledge is built—-this would be what Sellars called the "myth of the given." The scientific community embraces this and adopts mechanisms of checks and balances to convert the inter-subjectivity of any human knowledge into something approaching their ideals of objectivity. As argued by Kosso (1989), the convergence of inter-subjectivities becomes (our best shot at) objectivity.

It is impossible to fully demarcate science from other types of ways of knowing the world, but a big part of what characterizes the scientific endeavour are the rules of the game of asking and providing justifications that scientists play inside their community. All knowledge, be it philosophical, economical, religious, occult, or scientific depends on agreements inside a community of knowers, but in the case of science, the rules for achieving these agreements are based on rationality and on the aim of approaching some humanindependent truth about nature. Scientific knowledge is more reliable than other kinds of knowledge because it is generated inside a community focused on logical arguments in the pursuit of empirically successful theories.

Some of the common, minimal elements entering in this game of justifications within the scientific community include peer-reviewed publications, empirical tests-which can be given by experiments, observations, or computer simulations that ultimately are expected to reproduce empirical data-scientific conferences, and the structure of incentives within academia, which mostly rests on peer recognition. Oreskes (2019) says that what characterizes the epistemic value of science are the scientists themselves, in their commitment with the world and with science. As the many criticisms we mentioned above clearly show, reality is not so ideal in that scientists are humans, and they belong to societies, which makes them prone to mistakes and to misconduct. But there is still truth in what Oreskes says, and we would say that the epistemic value of science comes from the scientists themselves working together as a community with the high epistemic standards just mentioned.

Again, it is precisely the social character of scientific knowledge which makes it more reliable than other types of knowledge or discourses. In order to be accepted within the scientific community, scientists, regardless of their moral commitments to the world and to science (or the possible lack of those) have to accept the rules of their community, which were historically constructed so that the community is able to test scientific proposals, and to refine them in order to approach a better description of the natural world. Deviations from the rules of this game of justifications can and do happen. The scientific community 
is well equipped to deal with them because of its special characteristics: as a community, it is international, it values free exchange of information, a substantial portion of research is made by young researchers (under the guidance of more experienced ones), which opens the way to new challenges to accepted knowledge so that the justification game is continuously being played, etc. Even if some mistakes are made within the context of discovery, in the long run, the game of constantly justifying scientific knowledge warrants its reliability.

As mentioned above, the denial of this social aspect of science also has had very bad consequences in terms of relativization of scientific knowledge. In particular, when Popper's falsifiability denies any importance to the community of scientists and puts all the weight of scientific knowledge-its demarcation-on the possibility of a crucial experiment destructing the whole building of science at any moment, it gave way to examples of relativism with respect to science and mostly with respect to science which is against powerful interests. Science is a social endeavour, and it is precisely this fact which makes scientific knowledge more robust. The fact that some philosophers of science generated normative descriptions of how science is supposed to work has led to many confusions. Real-world science is more complex, and rich, than these philosophical idealizations.

Finally, scientific knowledge is social also in the sense that it does not match the beliefs of individual scientists, which can often be victims of several kinds of prejudices. The way to avoid false consensus within the scientific community is by making it as big as possible, so that all points of view and all backgrounds are represented. Scientific education and the inspiration of younger generations to be scientists play a vital role in this.

\section{Science Education and the Reliability of Science}

Along the preceding sections, we elaborated on some important criticisms to which science has been exposed, as well as a defence of it based on those elements of the scientific activity that shield scientific knowledge from those critiques. But the final aim of this article is to give an answer to the question of why and how it is important to teach science, both as a process and as a source of established knowledge. Having already given arguments to consider science as the best tool at hand to know the world, it is important now to elaborate on how to best bring this knowledge closer to the general population.

In this section, we analyse scientific education as the way towards population-wide scientific alphabetization. Before proceeding, two clarifications are in order. First, our confidence in scientific education is not blind, and we expose below some mistakes and shortcomings in the way this discipline has functioned through history, advancing a proposal for what are the aspects of the scientific endeavour deserving of more focus in curricula. Secondly, the discussion will not only deal with scientific education within formal education but will at the end sketch the need for including the broader spectrum of educational paths nowadays available.

We showed in Section 3 how some developments in philosophy of science were adopted by science educators in an unrefined way and were given a very radical interpretation, distorting the objectives of the original ideas. We mentioned Kuhn's ideas and how these are related to forms of social constructivism that are not adequate when we deal with scientific education, precisely because some of these extreme constructivist readings turn their back to the rational and objective character of scientific knowledge. As we discussed in the previous section, the scientific tradition encourages critical thinking, the focus on evidence, 
and the focus on understanding nature as the end-goal, as overpowering personal interests in the context of the scientific community.

The impact science has on society is mediated by the experiences we have of it, and a first such experience for a population having access to formal education are science classes. In the first schooling years, natural science teachers usually recognize the importance and the need for a phenomenal experience of the world, and its approximation through the naked senses-aiming for a continuous transformation from what is usually called 'common knowledge,' through 'school knowledge,' to finally arrive to 'scientific knowledge' (González, 2019, p. 215). However, this proposed continuity loses most of its weight if we consider that in fact there is an epistemic breach between the world of the senses and the world intelligible by science, as each kind of knowledge solves different kinds of problems (Bachelard, 1984, in González, 2019).

The epistemic breach mentioned in the previous paragraph directly appeals to the ways in which we experience nature. A Cartesian understanding of experience would make us distrust our sense perceptions of physical objects, as these are charged with subjectivity. However, Bachelard proposes that it is precisely the diversity and complexity of the sense experience that which allows us to attain a certain degree of objectivity. This can be understood observing how scientists must be open to the experience of new objects. Scientific observation is mediated by the different experimental environments that disclose certain aspects of the objects of the physical world, which guides the procedures to be implemented to reveal their identities. This allows for the experiential/experimental diversity to be strongly linked to rational understanding. Science is an open and continuous process of hypothesis depuration and correction of previous knowledge as a product of rational activity. The fact that scientists do not have privileged access to all phenomena in nature does not prevent them to have epistemic access to them (Rheinberger, 2005; Romero-Maltrana et al., 2019).

The educational programmes in science education have aimed to close the gap between science and daily experience, but the truth is that one can make practical decisions without the need for scientific knowledge, even when scientific knowledge would be implicitly used in the action at hand-such as when using technology. In other cases, we might have a certain basis of scientific knowledge, but it is not used for most of our daily activities. All this points to a change of priorities. The aim of science education would not only be to use science to solve individual problems, but also, and vitally, to learn and value the methods that the scientific community uses to attain reliable knowledge about the world.

Perhaps a more useful approach to the issue is by means of the notion of scientific alphabetization. This concept, introduced in the 1950s, can be further decomposed into various levels of alphabetization. Following Sjöström (2019), scientific alphabetization includes 3 levels: scientific alphabetization 'for scientists', that is to say for individuals that wish to become part of the scientific community, which implies mainly an advanced handling of scientific contents; scientific alphabetization at the level of procedures or action, where the focus is on the individuals' abilities to apply their knowledge about science on daily life problems and on the development of basic scientific abilities; and lastly the level of "critical' scientific alphabetization, which aims at the integration of scientific and non-scientific knowledge and abilities to the discussion and solution of societal issues.

To achieve these aims, some propose to include within formal educational programmes some aspects of history and philosophy of science (Matthews, 2014), while establishing relationships between scientific knowledge and other study areas, in order to generate an impact on the worldview of students, and on their predisposition to critically analyse their culture and ideas in a broader context. 
The science curriculum should provide young people with an understanding of some key 'ideas about science,' that is, ideas about the ways in which reliable knowledge of the natural world has been, and is being, obtained. (Reiss et al., 1999, p. 69).

On this, we would agree that teaching about science and doing science are quite different, and in fact, the distinction should be made between science education and scientific knowledge, between knowing science, and knowing about science. For this, some suggest emphasizing the tentative character of scientific knowledge (Lederman et al., 2002; McComas, 1996, 2002), or the absence of a unified scientific method. In contrast, we propose emphasizing both scientific content, as well as those elements identified in Section 5, particularly the robustness that emerge from science's particular social practices, which justify considering scientific knowledge as the most reliable source of knowledge about the material world.

As Pozo rightly clarifies:

Knowing how to read and understand a scientific text, interpret or draw a graph, differentiate two different interpretations of the same event, criticize different solutions to a health or environmental problem, are increasingly necessary general skills, which, even though having a specific content, require from the students something more than mastering those contents (Pozo, 1997, p. 98, our translation).

So that the ultimate objective of scientific education is not merely the learning of scientific knowledge, but also the development of abilities allowing individuals to have a basic, general, and correct understanding of the information that is daily presented to us in a scientific language.

Science, understood as a process, is not only the accumulation of theories, but also a structure of mechanisms of inquiry and justification that enabled the elaboration of such theories and that allow knowledge about the world to be in a constant state of improvement. If not only the contents but also the methods of science are valuable, then it is reasonable to extend this insight to the context of scientific education, in particular the inclusion of scientific abilities that will enable individuals to evaluate the pertinence of a given piece of information when taking decisions both at the personal and at the social level. Given the accelerated pace at which knowledge and information about various aspects of the world is generated, it is impossible to be prepared nor to prepare others for all the areas in which the present and future society requires our participation. Nonetheless, it is important to have a minimum state of scientific alphabetization, in order to know where to look for the most reliable sources of information. The challenge is big, and guiding principles and examples are needed, and we believe providing these examples can be one of the roles of science in our society.

Taking into account that education channels can be very diverse and dependent on the economic and cultural context, we believe there are three fronts for enhancement: firstly scientific education at the school level, for these are the individuals that will have to confront the consequences of the many bad environmental and economic decisions of our age; secondly, it is important to improve the scientific education that teachers receive during their own formation, as their own scientific alphabetization and didactical preparation is vital to address this educational need of future generations.

We acknowledge that this educational task is complex and long winded, in particular because it is difficult to change individuals' early beliefs, which tend to be very unscientific. This makes it strategically sound to find ways of influence as early as possible in order to prevent the consolidation of unscientific misconceptions. During the early stages of 
cognitive development, we are more adaptable and permeable to new knowledge (McLeod, 2018), so that to stimulate and encourage the development of critical thought, and the practice of participating in a collaborative but critical community, together with experiences that allow children to better know the functioning of the material world, seems like a good guiding light for the restructuring of scientific education curricula.

Lastly, given the speed of global changes (exemplified by the ongoing pandemic, by climate change, and by the possibility of peak oil, among others), it becomes urgent to not only educate about the aspects covered in Section 5 within formal channels that take 20 years, but instead in all possible education channels. To devise strategies for this goes beyond what we can discuss in this work, but we cannot avoid mentioning the relevance of this aspect, given the scale of the challenge we confront as a species. To aspire for the entire population to have a higher level of scientific alphabetization is an ambitious, but not impossible goal, which would require the appropriate investment of resources and time. Given that many of the issues discussed above have an urgent character, we would aim to reach population-wide scientific alphabetization at the second level discussed above, this is, scientific alphabetization at the level of procedures and action.

\section{Conclusions}

The last decades have seen the increasing dominance of voices claiming that scientific knowledge is not more reliable than any other kind of knowledge, because science is a human activity performed by a community of humans, turning scientific knowledge into a mere social construction. This discourse about science has arguably had strong effects on the perception that our societies have about scientific knowledge, and it has strongly affected the way scientific education is approached-this being an area that is of crucial importance for the well-functioning of current and future democratic societies.

It is probably naïve to think that personal beliefs will be replaced by scientific knowledge only by exposing students to the latter, in no small part because scientific evidence goes against deeply rooted ideologies and assumptions (Fackler, 2021; Lewandowsky et al., 2012; Sandoval, 2005; Sinatra et al., 2014). A direct opposition between these sets of beliefs ends up being counter-productive, reinforcing erroneous and deceptive beliefs. This does not go against the relevance of science education but aims to guide it using better pedagogical tools. To appeal to the social dynamics involved in the generation of scientific knowledge can contribute towards this goal. It is not sufficient to confront erroneous beliefs with complex explanations in order to convince students, but the objective is instead to involve the student within a process of evaluation of available evidence, teaching them to differentiate between evidence obtained through a systematic socially mediated process, from that stemming from intuitions or rhetorical tricks.

In this work, we argue that the importance of trusting science, and the necessity that such confidence on scientific claims is shared by as many people as possible, is clearer than ever. This is so not only despite the social character of science, but actually because of it. As any social enterprise, science is also subject to be influenced, directed, or co-opted by power or money, and it is exactly the social, uncentralized, open, and global character of science which serves as a powerful corrective mechanism, one that is unfortunately absent from other human activities. The dangers of ignoring scientific knowledge are clear all around us. Science should not be blindly accepted, but the recommendations of the scientific community should be listened to with care and weighted prominently in our political 
decisions. The menaces of climate change, pandemics, industrial disasters, among others are not to be taken lightly, and our collective minds would do well to listen to the consensus view of the scientists working on each of these topics. Alarms about these issues have been raised repeatedly in recent literature, considered as a pressing example the scientific consensus regarding the anti-vaccine movement (Kata, 2012; Hussain et al., 2018; Megget, 2020) or climate change (Dunlap \& McCright 2010; Lewandowsky et al. 2015).

Science is a human activity, and the objectivity of scientific knowledge is an ideal, a general aim of the scientific community which is only approximated by means of community-wide inter-subjectivity. Science is a game that scientists play following certain rules; rules which were designed to protect scientific knowledge from non-scientific influences, such as money, personal interests, and beliefs. It is thus precisely because science is developed by an international community of actors committed to these rules and that each claim must be contrasted against empirical evidence and that scientific knowledge is more reliable than other kinds of human knowledge. The consideration of these points has been mostly absent in the extant literature and constitutes our main contribution to the discussion.

We believe these aspects of the discussion on scientific knowledge should be part of the curricula of scientific education for every member of our democratic societies, in such a way that every collective decision taken by society is informed by our best scientific knowledge and that in turn the nature of this knowledge is fully grasped. In fact, we believe that these social aspects of the scientific endeavour should not only be taught as part of the formal curricula of science classes, but also be part of the education of citizens outside of these formal circuits. Science education should serve not only as a transmission of scientific knowledge to students, but also as an exploration of how science works. This includes many aspects of the social nature of science that the constructivists have been arguing for in these last decades, but also a detailed study of the mechanisms that the scientific community has for building inter-subjective claims that best approaches an objective knowledge of natural phenomena. In this way, we would avoid extreme views that point towards and unwarranted epistemic relativism.

Study programmes should aim for the generation of the knowledge and skills that are needed to tackle the challenges that societies confront nowadays and in the foreseeable future, but not only as an informational input. Conventional examples of scientific outputs always seem to yield a clear connection between causes and effect, giving students an incorrect impression of the workings of science, as emphasized by Pietrocola et al. (2021). A way to escape this is to pay attention to the social dynamics that lay behind the generation of scientific knowledge and to stress how these improve its reliability.

A commitment to science, as proposed by Valladares (2021), manifests in more opportunities to experience science in connection to everyday life, which translates into deeper participation, by which individuals and the collective understand science as a process, adopting scientific knowledge with greater conviction. Our vision in this article complements that of Valladares in that the scientific process is, among other things, a complex social activity. As emphasized above, the goal of scientific alphabetization should be considered as an ongoing process in itself, as the dynamism of science requires constant learning. This process benefits from a multi-disciplinary approach, with a goal to understand how to interpret the world from the perspectives offered by science, with the advantages and responsibilities that they entail, rather than to reach a certain level of expertise in this or that scientific discipline.

Moreover, it is important to recognise that scientific alphabetization is a context-dependent process. People cannot be classified as alphabetized or not alphabetized; the context in 
which they learn about science must be considered, as the positions students take about complex issues are affected by social factors (Ke et al., 2021). Note that these contextual social factors are independent of the social dynamics intra the global scientific community which can be regarded as a common culture. Nonetheless, we think that putting the focus on the latter can contribute to scientific alphabetization in each of the context referred to by Ke. Relevant differences in contexts are not only geographical but also temporal. A necessary condition for the teaching of science in schools is a historically informed concept of scientific development, leading to better knowledge and understanding of science (Terhart, 1988). These historical developments not only include the evolution of ideas about the natural world, but also the social dynamics that helped to the consolidation of these ideas.

We agree with Martin and Osorio (2003), when they say that 'A techno-scientific education that allows individuals to know the processes and handle the devices in their surrounding will not really educate citizens able to participate in a democracy unless it integrates, on top of the knowledge to analyse reality, and the skill to navigate it, strategies for the development of aptitudes and attitudes which are participative and open to dialog, the negotiation, and the decision making in relationship with the issues associated to scientific and technological development' (p. 175). But we believe that this presupposes what we propose here: it is necessary that we know and trust scientific knowledge for it to guide our political decisions.

It is not absurd to consider, and to teach about, the ways in which science and scientific knowledge are influenced by social dynamics, but avoiding extreme takes that relativize what is in fact our most reliable source of knowledge about the natural world. A way to avoid these exaggerated takes is to emphasize that this social character of science is in itself deeply involved with the high reliability of the knowledge it produces.

Funding This study was partially funded by Pontificia Universidad Catolica de Valparaíso, Grant $\mathrm{N}^{\circ}$ $039.374 / 2001$.

Code Availability Not applicable.

\section{Declarations}

Conflict of Interest The authors declare that they have no conflict of interest.

\section{References}

ATLAS, C., Yamamoto, S., Shapiro, M., Virzi, J., Werner, M., Venturi, M., ... \& Vivarelli, I. (2010). The simulation principle and performance of the ATLAS fast calorimeter simulation FastCaloSim (No. ATL-PHYS-PUB-2010-013). ATL-COM-PHYS-2010-838.

Bachelard, G. (1984). The new scientific spirit, trans. Beacon Press.

Ball, P., \& Maxmen, A. (2020). The epic battle against coronavirus misinformation and conspiracy theories. Nature, 371-374.

Barange, M., Cheung, W. W., Merino, G., \& Perry, R. I. (2010). Modelling the potential impacts of climate change and human activities on the sustainability of marine resources. Current Opinion in Environmental Sustainability, 2(5-6), 326-333.

Bastani, P., \& Bahrami, M. A. (2020). COVID-19 related misinformation on social media: A qualitative study from Iran. Journal of Medical Internet Research. https://doi.org/10.2196/189321

Berry, B. J., Bihari, J., \& Elliott, E. (2016). The limits of knowledge and the climate change debate. Cato Journal, 36, 589. 
Best, M. L., \& Wade, K. W. (2009). The internet and democracy: ¿Global catalyst or democratic dud? Bulletin of Science, Technology \& Society, 29(4), 255-271.

Betz, G. (2013). In defence of the value free ideal. European Journal for Philosophy of Science, 3(2), 207-220.

Bonate, P. L. (2011). Pharmacokinetic-pharmacodynamic modeling and simulation (Vol. 20). Springer.

Chakravartty, A. (2007). A metaphysics for scientific realism: Knowing the unobservable. Cambridge University Press.

Chen, S. Y., Anderson, S., Kutty, P. K., Lugo, F., McDonald, M., Rota, P. A., ... \& Seward, J. F. (2011). Healthcare-associated measles outbreak in the United States after an importation: Challenges and economic impact. Journal of Infectious Diseases, 203(11), 1517-1525.

Clark, M. A., Domingo, N. G., Colgan, K., Thakrar, S. K., Tilman, D., Lynch, J., ... \& Hill, J. D. (2020). Global food system emissions could preclude achieving the $1.5^{\circ}$ and $2{ }^{\circ} \mathrm{C}$ climate change targets. Science, 370(6517), 705-708.

Dunlap, R. E., \& McCright, A. M. (2010). Climate change denial: sources, actors and strategies. In Routledge handbook of climate change and society (pp. 270-290). Routledge.

Douglas, H. (2004). The irreducible complexity of objectivity. Synthese, 138(3), 453-473.

Fackler, A. (2021). When science denial meets epistemic understanding. Science \& Education, 30(3), 445-461.

Fernandes, N. (2020). Economic effects of coronavirus outbreak (COVID-19) on the world economy. Available at SSRN 3557504.

Flato, G., Marotzke, J., Abiodun, B., Braconnot, P., Chou, S.C., Collins, W., Cox, P., Driouech, F., Emori, S., Eyring, V. and Forest, C. (2014). Evaluation of climate models. In Climate change 2013: the physical science basis. Contribution of Working Group I to the Fifth Assessment Report of the Intergovernmental Panel on Climate Change (pp. 741-866). Cambridge University Press.

Franklin, A. (1994). How to avoid the experimenters' regress. Studies in History and Philosophy of Science Part A, 25(3), 463-491.

González, L. (2019). Del mundo de lo sensible al universo de lo inteligible en la enseñanza de las ciencias naturales. Pedagogía y Saberes, 50, 211-221.

Guyatt, G., Cairns, J., Churchill, D., Cook, D., Haynes, B., Hirsh, J., ... \& Tugwell, P. (1992). Evidencebased medicine: A new approach to teaching the practice of medicine. JAMA, 268(17), 2420-2425.

Hoyningen-Huene, P. (1987). Context of discovery and context of justification. Studies in History and Philosophy of Science Part A, 18(4), 501-515.

Hussain, A., Ali, S., Ahmed, M., \& Hussain, S. (2018). The anti-vaccination movement: a regression in modern medicine. Cureus, 10(7), e2919. https://doi.org/10.7759/cureus.2919

Irzik, G., \& Nola, R. (2011). A family resemblance approach to the nature of science for science education. Science \& Education, 20(7), 591-607.

Irzik, G., \& Nola, R. (2014). New directions for nature of science research. In International handbook of research in history, philosophy and science teaching (pp. 999-1021). Springer.

Jerneck, M. (2017). Financialization impedes climate change mitigation: Evidence from the early American solar industry. Science advances, 3(3), e1601861.

Johnson, N. F., Velásquez, N., Restrepo, N. J., Leahy, R., Gabriel, N., El Oud, S., \& Lupu, Y. (2020). The online competition between pro-and anti-vaccination views. Nature, 582(7811), 230-233.

Kata, A. (2012). Anti-vaccine activists, Web 2.0, and the postmodern paradigm-An overview of tactics and tropes used online by the anti-vaccination movement. Vaccine, 30(25), 3778-3789.

Ke, L., Sadler, T. D., Zangori, L., \& Friedrichsen, P. J. (2021). Developing and using multiple models to promote scientific literacy in the context of socio-scientific issues. Science \& Education, 30(3), 589-607.

Koskinen, I. (2020). Defending a risk account of scientific objectivity. The British Journal for the Philosophy of Science, 71(4), 1187-1207.

Kosso, P. (1989). Science and objectivity. The Journal of Philosophy, 86(5), 245-257.

Kremer, M. (2002). Pharmaceuticals and the developing world. Journal of Economic Perspectives, 16(4), 67-90.

Kuhn, T. S. (1962). The structure of scientific revolutions. University of Chicago Press.

Ladyman, J., Ross, D., Spurrett, D., \& Collier, J. G. (2007). Everything must go: Metaphysics naturalized. Oxford University. (Press on demand).

Laudan, L. (1981). A confutation of convergent realism. Philosophy of Science, 48(1), 19-49.

Laudan, L. (1983). The demise of the demarcation problem. In Physics, philosophy and psychoanalysis, pages 111-127. Springer. 
Lederman, N. G., Abd-El-Khalick, F., Bell, R. L., \& Schwartz, R. S. (2002). Views of nature of science questionnaire: Toward valid and meaningful assessment of learners' conceptions of nature of science. Journal of Research in Science Teaching, 39(6), 497-521.

Lewandowsky, S., Ecker, U. K. H., Seifert, C., Schwarz, N., \& Cook, J. (2012). Misinformation and its correction: Continued influence and successful debiasing. Psychological Science in the Public Interest, 13, 106-131.

Lewandowsky, S., Oreskes, N., Risbey, J. S., Newell, B. R., \& Smithson, M. (2015). Seepage: Climate change denial and its effect on the scientific community. Global Environmental Change, 33, 1-13.

Loving, C. C., \& Cobern, W. W. (2000). Invoking Thomas Kuhn: What citation analysis reveals about science education. Science \& Education, 9(1), 187-206.

Lukas, W. (2012). Fast simulation for ATLAS: Atlfast-II and ISF. In Journal of Physics: Conference Series (Vol. 396, No. 2, p. 022031). IOP Publishing.

Luper, S. (2004). Epistemic relativism. Philosophical. Issues, 14, 271-295.

Lyotard, J. F. (1979). La condition postmoderne: rapport sur le savoir. Minuit.

Malhi, Y., Roberts, J. T., Betts, R. A., Killeen, T. J., Li, W., \& Nobre, C. A. (2008). Climate change, deforestation, and the fate of the Amazon. Science, 319(5860), 169-172.

Martín, M. y Osorio, C. (2003). Educar para participar en ciencia y tecnología. Un proyecto para la difusión de la cultura científica. Revista Iberoamericana de Educación, 32, 165-210.

Matthews, M. R. (2002). Thomas Kuhn's impact on science education: What lessons can be learned? Science Education, 88(1), 90-118.

Matthews, M. R. (2014). Science teaching: The contribution of history and philosophy of science. Routledge.

McComas, W. F. (1996). Ten myths of science: Re-examining what we think we know about the nature of science. School Science and Mathematics, 96(1), 10-16.

McComas, W. F. (2002). The principal elements of the nature of science: Dispelling the myths. In The nature of science in science education, pages 53-70. Springer.

McComas, W. F., Clough, M. P., \& Almazroa, H. (1998). The role and character of the nature of science in science education. In The nature of science in science education (pp. 3-39). Springer.

McLeod, S. (2018). Jean Piaget's theory of cognitive development. Simply Psychology, 1-9.

Oreskes, N. (2019). Why trust science? Princeton University Press.

Megget, K. (2020). Even Covid-19 can't kill the anti-vaccination movement. BMJ, 369, m2184. https:// doi.org/10.1136/bmj.m2184

Oreskes, N., \& Conway, E. M. (2011). Merchants of doubt: How a handful of scientists obscured the truth on issues from tobacco smoke to global warming. Bloomsbury Publishing USA.

Peters, M. (1995). Education and the postmodern condition: Revisiting Jean-Francois Lyotard. Journal of Philosophy of Education, 29(3), 387-400.

Pietrocola, M., Rodrigues, E., Bercot, F., \& Schnorr, S. (2021). Risk society and science education. Science \& Education, 30(2), 209-233.

Phillips, D. (2019). Bolsonaro declares 'the Amazon is ours' and calls deforestation data 'lies'. The Guardian, 19.

Psillos, S. (1999). Scientific realism: How science tracks truth. Routledge.

Pozo, J. I. (1997). La crisis de la educación científica: ¿volver a lo básico o volver al constructivismo? Alambique: Didáctica de las ciencias experimentales, 14, 91-104.

Reiss, M. J., Millar, R., \& Osborne, J. (1999). Beyond 2000: Science/biology education for the future. Journal of Biological Education, 33(2), 68-70.

Resnik, D. B. (2007). The price of truth: How money affects the norms of science. Oxford University Press.

Rheinberger, H. J. (2005). Gaston Bachelard and the notion of "phenomenotechnique." Perspectives on Science, 13(3), 313-328.

Rhodes, R. (2012). The making of the atomic bomb. Simon and Schuster.

Rocca, A. V. (2011). La posmodernidad. Nuevo régimen de verdad, violencia metafísica y fin de los metarrelatos. Nómadas. Critical Journal of Social and Juridical Sciences, 29(1). https://www.redal yc.org/articulo.oa?id=18118941015

Romero-Maltrana, D., Benitez, F., Vera, F., \& Rivera, R. (2019). The 'nature of science' and the perils of epistemic relativism. Research in Science Education, 49(6), 1735-1757.

Sandoval, W. A. (2005). Understanding students' practical epistemologies and their influence on learning through inquiry. Science Education, 89(4), 634-656.

Sankey, H. (2011). Epistemic relativism and the problem of the criterion. Studies in History and Philosophy of Science Part A, 42(4), 562-570. https://doi.org/10.1016/j.shpsa.2011.09.012 
Sinatra, G. M., Kienhues, D., \& Hofer, B. K. (2014). Addressing challenges to public understanding of science: Epistemic cognition, motivated reasoning, and conceptual change. Educational Psychologist, 49(2), 123-138.

Sjöström, J. (2019). Didactic modelling for socio-ecojustice. Journal for Activist Science and Technology Education, 1, 10. https://doi.org/10.33137/jaste.v10i1.32916

Sugerman, D. E., Barskey, A. E., Delea, M. G., Ortega-Sanchez, I. R., Bi, D., Ralston, K. J., ... \& LeBaron, C. W. (2010). Measles outbreak in a highly vaccinated population, San Diego, 2008: role of the intentionally undervaccinated. Pediatrics, 125(4), 747-755.

Symonds, A. (2019). Amazon rainforest fires: here's what's really happening. New York Times.

Tayloe, D. T. (2021). Immunization messaging, communication, and outreach amidst the growing anti-vaccine movement. North Carolina Medical Journal, 82(2), 118-121.

Terhart, E. (1988). Philosophy of science and school science teaching. International Journal of Science Education, 10(1), 11-16.

Tobin, K. (1999). Constructivism in science education: Moving on. Yearbook-National Society for the Study of Education, 1, 227-253.

Tollefson, J. (2017). Trump pulls United States out of Paris climate agreement. Nature News, 546(7657), 198.

Valladares, L. (2021). Scientific literacy and social transformation. Science \& Education, 30(3), 557-587.

Van Gunsteren, W. F., \& Berendsen, H. J. (1990). Computer simulation of molecular dynamics: Methodology, applications, and perspectives in chemistry. Angewandte Chemie International Edition in English, 29(9), 992-1023.

Vattimo, G., \& Webb, D. (1992). The transparent society (p. 40). Polity Press.

Worrall, J. (1989). Structural realism: The best of both worlds? Dialectica, 43(1-2), 99-124.

Publisher's Note Springer Nature remains neutral with regard to jurisdictional claims in published maps and institutional affiliations. 